${ }^{3}$ Eng K, Ranson JHC, Localio SA. Resection of the perforated segment: a significant advance in treatment of diverticulitis with free perforation or abscess. Am f Surg 1977;133:67-72.

- Pledger HG, Buchan R. Deaths in children with acute appendicitis. $\mathrm{Br}$ Medf 1969 ;iv:466-70.

5 Tagart REB. General peritonitis and haemorrhage complicating colonic diverticular disease. Ann R Coll Surg Eng 1974;55:175-83.

6 Barabas AP. Perforated diverticulitis. Br Med f 1970;iii :767-8.

7 Fielding LP, Stewart-Brown S, Blesovsky L. Large-bowel obstruction caused by cancer: a prospective study. $\mathrm{Br}$ Med $\mathcal{F} 1979$;ii :515-7.

${ }^{8}$ Stewart DJ. Antibiotic lavage in the prevention of intraperitoneal sepsis. Am R Coll Surg Eng 1978;60:240-3.

- Stewart DJ, Matheson NA. Peritoneal lavage in faecal peritonitis in the rat. Br $\mathcal{F}$ Surg 1978;65:57-9.

${ }^{10}$ Hudspeth AS. Radical surgical debridement in the treatment of advanced generalised bacterial peritonitis. Arch Surg 1975;110:1233-6.

11 Munro A, Jones PF. Operative intubation in the treatment of complicated small bowel obstruction. Br $\mathcal{F}$ Surg 1978;65:123-7.

12 Burnett WE, Brown GR, Rosemond GP, Caswell HT, Buchor RB, Tyson RR. The treatment of peritonitis using peritoneal lavage. Ann Surg $1957 ; 145: 675-81$.

13 Noon GP, Beall AC, Jordan GL, Riggs S, De Baker ME. Clinical evaluation of peritoneal irrigation with antibiotic solution. Surgery $1967 ; 62$ 73-8.

14 Stewart DJ, Matheson NA. Peritoneal lavage in appendicular peritonitis. BrF Surg 1978;65:54-6.

${ }^{15}$ McKenna JP, Currie DJ, MacDonald JA, Mahoney LJ, Finlayson DC, Lanskail DJ. The use of continuous postoperative peritoneal lavage in the management of diffuse peritonitis. Surg Gynecol Obstet 1970;130: 254-8.

${ }^{16}$ Neely J, Catchpole B. Ileus: the restoration of alimentary-tract motility by pharmacological means. Br F Surg 1971;58:21-8.

\section{Recurrent abdominal pain in childhood}

One schoolchild in every seven or so suffers from recurrent abdominal pain, and yet in most cases no organic cause is found. ${ }^{1}$ So how extensively should such children be investigated ? An adequate history and thorough physical examination are absolutely essential, and, though a few routine investigations (full blood count, sedimentation rate, and urinanalysis and culture) should be performed, often by that stage the futility of further studies will have become clear. ${ }^{2} \mathrm{~A}$ longterm follow-up of recurrent abdominal pain by Stickler and Murphy ${ }^{3}$ showed that organic disease is missed very rarely, but that it should always be suspected where there is loss of weight and anaemia. In general, the physician has to rely on his common sense and judgment in determining which investigations are necessary. ${ }^{1-5}$

How then, should paediatricians respond to the periodic claims that recurrent abdominal pain in childhood is due to some form of dietary influence? Fat intolerance, ${ }^{6}$ generalised food allergy, ${ }^{7}$ and, most recently, lactose intolerance ${ }^{8} 9$ have all been incriminated. Soothill has stated that there is now impressive preliminary evidence of food allergy in nearly every organ ${ }^{10}$ and called for less unscientific criticism of the claims for the value of elimination diets. Soothill's plea is perfectly reasonable; but the claims, in their turn, should be based on studies that are scientifically sound. In the case of recurrent abdominal pain in childhood such studies are very few. The claims for the effectiveness of elimination diets ${ }^{6-9}$ should not be surprising: the amount of personal interest shown by the doctor and his enthusiasm for a treatment are known to enhance its value. As Rachman and Phillips ${ }^{11}$ have noted, "uncontrolled studies of therapeutic drug actions are claimed to be effective five times more frequently than independently assessed investigations." The same probably holds true for studies of dietary elimination.
More studies are needed along the lines of that of Atherton and his colleagues, ${ }^{12}$ who used a double-blind controlled design to show the value of an egg-free, milk-free diet in infantile eczema. ${ }^{12}$ At present there is insufficient evidence to discount Apley's view that in almost all of children with recurrent abdominal pain the underlying disorder is psychological. ${ }^{13}$ Indeed, the effectiveness of various psychological methods of treatment ${ }^{14-16}$ would be hard to explain if the cause were, as often as is claimed, dietary intolerance.

The diagnosis of emotionally determined recurrent abdominal pain is based on the history, the absence of any detectable organic disease, and the evidence of emotional disorder in the child or his family or both. Often the paediatrician will need to meet and observe the family before any emotional problems become apparent. The "examination" of a family is as important in making a diagnosis of emotional disorder as is the physical examination when making a diagnosis of organic disorder. Failure to meet the family often accounts for lack of recognition of primary emotional problems and may even aggravate them. ${ }^{16} \mathrm{~A}$ school report may also highlight relevant factors.

When recurrent abdominal pain is emotionally determined its effective management may be considered in three stages. Firstly, the physician must gain a clear understanding of the psychosocial factors, whether these be, for example, anxiety or sadness in the child, problems of learning or adjustment at school, or dysharmony or prolonged stress in the family. Secondly, he should explain to the child and the parents how and why the possibilities of organic disorder have been excluded and how tension may present as pain. "It is useful to draw on analogies with common symptoms such as headache to explain how quite genuine pain can result from tension or anxiety." Thirdly, he should help the family to find ways of alleviating contributory stresses. They should be encouraged to talk about their worries and upsets-"to blow off steam"thus reducing the need for stresses to be converted into somatic symptoms. Problems at school and home should be discussed and possible solutions explored. If the family dysfunction is severe or prolonged the help of a social worker, psychologist, or psychiatrist may be sought as a preliminary to more elaborate forms of treatment. Drugs have no obvious place in the treatment of recurrent abdominal pain. ${ }^{1-5} 13$

Both the degree to which the child can be helped and the time required to accomplish this vary. ${ }^{4}$ Symptoms may disappear after one interview or persist into adult life. Nevertheless, follow-up studies indicate that the outlook is much better for those children who receive some form of psychological help, however informal. ${ }^{1}$ More intensive family therapy seems of value in some cases. ${ }^{4} 1415$

Physicians who doubt the importance of psychological factors in recurrent abdominal pain in childhood need to balance their fears of overlooking serious progressive disease ${ }^{3}$ with the danger that they themselves may help to perpetuate the illness by well-meaning but never-ending efforts to find a physical cause. ${ }^{13}$ There should no longer be any dispute about the need for a rapidly initiated psychosomatic approach. ${ }^{16} 17$

1 Recurrent pain. In: Apley J, McKeith R, Meadow R, eds. The child and his symptoms. 3rd ed. Oxford: Blackwell, 1978:60-7.

2 Dodge JA. Recurrent abdominal pain in children. Br Med f 1976;i:385-7.

3 Stickler GB, Murphy DB. Recurrent abdominal pain. Am $\mathcal{f}$ Dis Child $1979 ; 133: 486-9$.

4 Green M. Diagnosis and treatment: psychogenic, recurrent abdominal pain. Pediatrics $1967 ; 40: 84-9$.

${ }^{5}$ MacKeith R, O'Neill D. Recurrent abdominal pain in children. Lancet 1951 ;ii :278-82.

6 Childs P. Dietary fat, dyspepsia, diarrhoea and diabetes. Br $\mathcal{F}$ Surg 1972 ; 59:669-95. 
7 McKarness R. Not all in the mind. London : Pan, 1976.

8 Barr RG, Levine MD, Watkins JB. Recurrent abdominal pain of childhood due to lactose intolerance. A prospective study. $N$ Engl f Med $1979 ; 300$ :1449-52.

- Liebman WM. Recurrent abdominal pain in children: lactose and sucrose intolerance, a prospective study. Pediatrics 1979;64:43-5.

10 Soothill JF. Elimination diets in childhood. Br Med F 1980;280:401-2.

11 Rachman SJ, Philips C. Psychology and medicine. Harmondsworth: Penguin, 1978.

12 Atherton D, Sewell M, Soothill JF, Wells RS, Chivers C. A double-blind controlled crossover trial of an antigen-avoidance diet in atopic eczema. Lancet 1978 ; : $401-3$.

13 Apley J. The Child with abdominal pains. 2nd ed. Oxford: Blackwell, 1975.

14 Apley J, Hale B. Children with recurrent abdominal pain: how do they grow up ? Br Med F 1973; ;iii:7-9.

${ }^{15}$ Berger HG, Honig PJ, Liebman R. Recurrent abdominal pain: gaining control of the symptom. Am $\mathcal{F}$ Dis Child 1977;131:1340-4.

16 Hughes MC, Zimin R. Children with psychogenic abdominal pain and their families. Clin Pediat 1978;17:569-73.

17 Weller S. The patient is a family. World Medicine $1975 ; 10: 18-20$.

\section{Leber's optic neuropathy}

The study of hereditary optic neuropathy dates from Theodor Leber's paper published in 1871, though von Graefe had reported the condition in three brothers in 1858. Despite the relative rarity of Leber's disease some remarkably extensive pedigrees have been compiled. Young men are predominantly affected but transmission is by women, suggesting an $\mathrm{X}$-linked recessive inheritance. In many families, however, the hereditary pattern does not conform to conventional Mendelian principles. No affected man has transmitted either the carrier state or the disease, and symptomless female carriers transmit not only the disease to half or more of their sons but also the carrier state to most of their daughters. Moreover, $10-20 \%$ of female carriers $(30-40 \%$ in some Japanese families) may themselves manifest the disease. ${ }^{12}$

Fresh information has appeared recently ${ }^{3}$ about a family in Australia in which blindness due to Leber's disease was reported originally in 1921.4 This family has been traced back over 160 years to the marriage of a Chinese seaman to an Irish girl and now comprises 91 members in six generations, with 23 men and seven women affected. The onset was usually in the late teens or early twenties with a range of 5 to 49 years. Twins have been affected at the same age, ${ }^{5}$ but the variation in the age of onset suggests that an environmental factor may also contribute. ${ }^{6}$ Typically a young man develops acute or subacute failure of vision; deterioration takes place over days, weeks, or months, stopping short of complete blindness, and improvement is unusual. Both eyes may be affected simultaneously, or symptoms may develop in the second eye within a few days or months and almost invariably within a year. In two of the Australian patients, aged 42 and 19, only one eye had been affected after 12 and 14 years respectively.

The impaired vision, sometimes with sluggish pupillary responses, is usually associated with a bilateral central scotoma and sometimes with peripheral constriction of the visual fields. Optic atrophy starts in the papillomacular fibres, resulting in temporal pallor; later more extensive disc pallor develops, with a reduction in the number of small vessels crossing the disc margin and attenuation of retinal arterioles. In some cases the retinal vessels show a striking tortuosity. A further feature is defective colour vision, an acquired dyschromatopsia of the red-green axis. These findings have been considered diagnostic of Leber's optic neuropathy ${ }^{7}$ and should make invasive investigations unnecessary. If the family history does not confirm the diagnosis and if there is any doubt, other forms of optic neuropathy and particularly those due to compressing lesions must be considered. In the acute stage of Leber's optic neuropathy there is a fleeting papillitis with blurring of the disc margins, swelling and glistening of the nerve fibre layer around the disc, and irregular dilatation of the peripapillary capillaries without abnormal vascular permeability on fluorescein angiography. ${ }^{8}$ Pain in the eye aggravated by movement, which is a common presenting symptom in optic neuritis due to multiple sclerosis, has been reported in only a few cases of Leber's optic neuropathy, and transient visual blurring (Uhthoff's syndrome) is also rare. ${ }^{9}$ In a few families with Leber's optic neuropathy some members have had psychiatric and other neurological deficits of a diffuse type, ${ }^{610}$ including an encephalitic syndrome, ${ }^{11}$ and also disorders outside the nervous system.12 In many, however, optic neuropathy is the only manifestation.

According to one hypothesis Leber's optic neuropathy may be due to an inborn metabolic inability to detoxicate cyanide. Low plasma and urinary concentrations of thiocyanate have been found in some affected patients, ${ }^{210}$ and further support comes from the fact that smoking and urinary infections (both of which may lead to a rise in concentrations of cyanide) aggravate the condition. ${ }^{13}$ Nevertheless, neither treatment with hydroxycobalamin (which detoxicates cyanide) nor large doses of steroids has halted the failure of vision in the first affected eye nor prevented visual failure from developing in the second eye.?

At necropsy the few cases of Leber's disease studied ${ }^{13} 14$ have shown extensive axonal degeneration and loss of myelin in the central portion of the optic nerves. No case has been studied histologically in the early stage of the disease, and in view of the uncertain nature of the initial lesion in the optic nerve every opportunity should be taken to examine symptomless eyes in those at risk in families with the disease.

Visual evoked potentials have proved to be a sensitive index of optic nerve lesions in multiple sclerosis ${ }^{15}$ and other conditions, ${ }^{16}$ and have now been used to explore the unsolved problems in Leber's optic neuropathy. ${ }^{317}$ In advanced visual impairment the response appears to be absent. In patients with less severe lesions a marked reduction in amplitude with desynchronisation leading to a widened or bifid response is consistent with loss of nerve fibres with demyelination. In contrast to multiple sclerosis, sequential visual evoked responses deteriorate and there is no appreciable recovery of vision. Latencies have, however, been normal in symptomless eyes, even in those which later developed the disease, so that the technique is of no use as a screening test. Nevertheless, minor morphological abnormalities of the visual evoked responses were found in some symptomless males at risk and in some obligate and possible female carriers, with or without ophthalmic abnormalities.

Possibly in some cases identifying the carrier state or making a presymptomatic diagnosis would be feasible, though the absence of abnormalities in the visual evoked responses does not necessarily imply immunity. Asymptomatic abnormalities have been found in some descendants from male lineages, but these may represent separately inherited traits or partial forms of Leber's disease. We have to consider alternative, nonMendelian modes of vertical transmission, including mitochondrial inheritance, ${ }^{18}$ and cytoplasmic or transplacental transfer of an agent, possibly viral. ${ }^{19}$ Meanwhile both the aetiology and the mode of transmission of Leber's optic neuropathy remain a mystery. 